\title{
A escrita combativa de Cipriano Barata
}

Eide Sandra Azevêdo Abrêu

N A “Introdução” da coletânea Sen1 tinela da liberdade e outros escritos (1821-1835), o historiador Marco Morel, responsável pela edição e pela organização dos textos de Cipriano Barata nela contidos, afirma, com razão, que

Conhecer uma época ou determinados temas pelo prisma de uma trajetória individual é um dos desafios mais instigantes. Ainda mais no caso aqui publicado, quando o personagem teve trajetória singular e até inversa da maioria dos “grandes nomes" que são lembrados historicamente... (p.15)

E podemos acrescentar: mais ainda quando essa trajetória individual é apresentada por meio dos textos produzidos pelo protagonista em seu combate, escritos que nos trazem de maneira muito forte a vitalidade, a argúcia, as contradições e a inteligência com que o realizou. E nos abrem portas para adentrar de modo mais intenso na pesquisa sobre o período em que foram redigidos.

Ao tornar facilmente acessíveis tais textos, a publicação auxilia a promover o conhecimento da prodigiosa expressão da liderança considerada a mais influente de uma das vertentes do liberalismo formulado no Brasil do século XIX, vertente que costuma ser chamada de liberalismo "exaltado", ou mesmo "radical". Nesse sentido, o livro contribui para o aprofundamento do debate sobre os significados do liberalismo na história do Brasil, que tem estado há muito tempo marcado pela presença de esquemas de interpretação extensamente utilizados por historiadores e cientistas sociais, esquemas tão atraentes quanto simplificadores, e que estão ainda bastante difundidos. Eles têm sido felizmente, há algumas décadas, questionados de modo contundente, com base em aprofundadas pesquisas históricas. E a coletânea organizada por Marco Morel vem trazer à comodidade das prateleiras das livrarias um valioso material para a continuidade desse trabalho.

É difícil que esquematismos possam resistir à complexidade e à fluência caudalosa da escrita de Cipriano Barata, que se estende por mais de 800 das 935 páginas da edição. Lidos com atenção, esses textos desestabilizam estigmas e também idealizações que possam existir na mente do leitor, seja em relação à história do liberalismo no país, seja particularmente a respeito do autor e de suas concepções. São jornais, manifestos e outros documentos que se estendem do período em que transcorreu o processo de independência do Brasil até meados da década de 1830, passando por momentos especialmente tensos da luta política, tais como os debates das Cortes de Lisboa, o fechamento da Constituinte e a outorga da Constituição, o esmagamento da Confederação do Equador, o processo que levou à abdicação de $\mathrm{D}$. Pedro I e os enfrentamentos que a sucederam. Esses e outros acontecimentos surgem nos textos de maneira muito intensa e vertiginosa. Isso porque, além da eloquência vibrante do autor, tais escritos fizeram parte das violentas lutas políticas travadas na década de 1820 e na primeira metade da década de 1830. Constituíam visivelmente intervenções do autor nessas lutas, sendo instrumentos por meio dos quais Barata buscava combater adversários e arregi- 
mentar prosélitos, no intuito de viabilizar a concretização de um projeto de Estado que destoava do que veio a prevalecer.

São escritos que impressionam vivamente, porque estão carregados de reflexão, erudição, pregação política e, ao mesmo tempo, uma agressividade vigorosa, que se expressa em insultos a adversários e, especialmente, em uma grande capacidade de satirizar e ironizar, resultante de refinamento de observação e inventividade singulares. São textos que também fascinam pelas contradições que neles é possível encontrar, e pela simultaneidade de cálculo e desbragamento no modo como o autor ataca seus adversários, muitos deles personagens bastante enaltecidos em obras das mais conhecidas a respeito do período, personagens que se tornaram, nos desdobramentos da história e da memória, heróis nacionais. Revelam a combinação de racionalidade intensa, na formulação dos argumentos, e violência na paixão com que alvejam os ocupantes do poder, empenhados esses em instituir uma organização do poder político diversa da almejada por Barata. Uma amostra dessa combinação se encontra nos textos do período da Constituinte, em que os principais alvos eram os ministros Andradas, especialmente José Bonifácio, que é ridicularizado em ataques como este:

[...] estando o Excelentíssimo Senhor José Bonifácio Ribeiro de Andrada em uma pequena Chácara ou Sítio de terras plantando café e abóboras, foi de lá tirado e uma promoção deu o salto mortal para Primeiro-Ministro da $\mathrm{Na}$ ção Brasileira, ficando elevado ao respeitável lugar em que se acha, passando de Naturalista roceiro, Senhor de poucas terras e escravos, a pôr e dispor, puxar e repuxar, mandar devassar impiamente, prender, perseguir, degra- dar sem forma de justiça, assolar com Cartas Brancas, dar hábitos e mercês, e ofícios a torto e a direito, e finalmente despolitizar e tiranizar, e fazer o que é de seu gosto na Nação Brasileira que, calada e fria, o observa até feito ilegal e nulamente Deputado nas Cortes Soberanas, para tornar írrito e sem efeito tudo quanto se decretar, e armar barulhos no Brasil, que podem provocar a desunião das Províncias na crise atual, com prejuízo do nosso adorado Imperador, que é sobre quem refletem todas as vozes e movimentos dos nossos negócios políticos. (p.295)

Nesse momento, Barata poupa o imperador ("adorado"), que, segundo diz, não estaria percebendo o que acontecia, "iludido pelo canto das Sereias aduladoras que o cercam" (p.340), e insiste no ataque aos Andradas: “a família destes Senhores é tida e havida por assassina e feroz. Eles têm as mãos banhadas em sangue humano" (p.368).

José Bonifácio teria sido, segundo Barata, o principal responsável pela manutenção de práticas absolutistas no momento dos trabalhos da Constituinte, com o estabelecimento de um "sistema de terror", fundado em espionagem, denúncias, devassas, ameaças e até assassinatos, com o objetivo de aniquilar qualquer oposição dentro ou fora da assembleia (p.320-5 e p.333). O autor expõe em alguns números a circunstância de sua própria vida estar em risco, alvejada por manobras assassinas do ministério (p.586). Nesse contexto, não haveria tranquilidade alguma para os deputados trabalharem, motivo que, juntamente com outros, fundamenta as afirmações veementes e convincentes, feitas por Barata, da ilegitimidade da Constituinte. É um questionamento feito com o uso de argumentos e princípios liberais, mas 


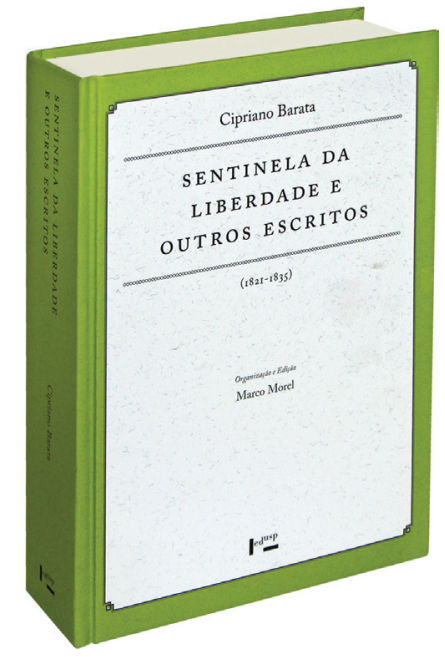

BARATA, Cipriano. Sentinela da liberdade e outros escritos (1821-1835). Org. Marco Morel. São Paulo: Edusp, 2008.

também com o recurso à ironia e à sátira. Os trabalhos da Constituinte, que teriam sido comprometidos pelo "terror" estabelecido pelo ministério, são assim apresentados por Barata:

Todos os Ilustres Senhores Deputados obram de um modo tal que parece que os nossos Estados Gerais estão na Costa da Mina, onde os Vassalos, míseros escravos, se cobrem de terra e pó quando se acham na presença do Rei, e tremem abaixando a voz quando proferem o seu nome. Os Senhores Andradas, segundo todas as demonstrações, dominam o Soberano Congresso. O Senhor Antonio Carlos, como Mestraço, só usa de frases embrulhadas e sesquipedais palavras, e todos falam a linguagem da condescendência mais nojenta, e quando aparece uma boa asneira, por exemplo, uma verdade abafada, um sofisma, um erro crasso de direito, etc., gritam quase todos com as bocas mui abertas - apoiado, apoiado. (p.321)
Tais ataques aos Andradas e ao modo como estava sendo elaborada a Constituição foram feitos por Barata no jornal Sentinela da Liberdade, que tem 88 dos seus números transcritos na coletânea. São críticas que se espraiam pelos 56 números publicados entre 23 de abril e 15 de novembro de 1823, em Pernambuco, antes do aprisionamento do autor, por "ocultas ordens vindas do Rio" (p.586). Nos textos desse período, ao mesmo tempo que ataca seus adversários, o autor se posiciona em relação a uma série de questões, defendendo: liberdade de imprensa, liberdade e segurança individuais, submissão do comando das armas ao poder civil das províncias, câmara única para o Legislativo, inexistência de veto absoluto pelo Imperador, exclusividade da iniciativa das leis ao Corpo Legislativo, retirada do comando das armas do Imperador, responsabilidade dos ministros de Estado e magistrados, instituição do Tribunal dos Jurados no cível e criminal, extinção da fidalguia hereditária, dos morgados, dos privilégios e isenções "de classes". Tais medidas, que são advogadas no contexto das guerras da independência e das lutas pertinentes à construção do Estado nacional, se articulam num projeto de Constituição que instituiria um governo liberal constitucional e federativo, que é defendido por Barata com tom e fórmulas de pregação. $\mathrm{E} \mathrm{o}$ autor, numa passagem em que demonstra claramente o destino das suas investidas, afirma que esse projeto atenderia aos interesses daqueles que não fizeram "este Império para meia dúzia de famílias do Rio de Janeiro, São Paulo e Minas desfrutarem" (p.287).

Barata foi preso em novembro de 1823, e publicou ainda um último número da Sentinela (p.581-7). Somente 
retomou a edição do jornal sete anos depois, quando foi libertado. Na nova fase, publicou em Salvador 22 números, dos quais cinco são reproduzidos na coletânea. São textos de 1831, de pouco antes de seu novo aprisionamento em abril desse ano, em momento próximo ao da abdicação do imperador.

Nessa fase, os maiores alvos da escrita indignada de Barata são os "moderados", agrupamento liberal que é atacado de maneira bastante violenta, ao serem seus membros chamados, por exemplo, de "servis aduladores do poder", "abjetos hipócritas, debaixo da capa de moderados", "egoístas velhacos, serpentes tentadoras saídas do abismo, e traidores à Pátria" (p.652-3). Contra a "fingida moderação", o autor expõe os princípios daqueles que pugnariam pelo estabelecimento, no Império constitucional, de um "governo federativo", correligionários que ele chama de "liberais firmes" (p.703).

Os adversários de Barata manobram para seu novo encarceramento, em abril de 1831, mas dessa vez ele continua a publicação do jornal, mesmo que de forma intermitente. Na coletânea, há oito números dos 36 que foram escritos nesse período, sob as regências.

Nesses textos, é alvejado diretamente o ex-imperador, antes poupado de críticas diretas, e agora sempre chamado de “Tirano Demônio D. Pedro I" (p.768), "Demônio assassino" (p.772), "celerado assassino" (p.777). A intenção de Barata é combater os chamados caramurus, partidários da restauração do poder de D. Pedro I, na continuidade da defesa do projeto de governo federativo. Essa implicou a manutenção da crítica contundente aos "moderados" ocupantes do poder, que Cipriano acusa de manuten- ção da política centralizadora do primeiro reinado e de práticas absolutistas.

$\mathrm{Na}$ sexta e última parte da coletânea, são reproduzidos sete números da Sentinela da liberdade, de um período logo posterior à libertação de Barata, em 1834 (p.867), e no primeiro deles há a indicação de que outro redator publica o jornal, no lugar de Barata. O organizador da coletânea, em nota de rodapé, interpreta que apenas esse número teria sido escrito pelo autor substituto (p.871). Mas é possível que a informação constante no jornal não dissesse respeito somente àquele primeiro número dessa fase, e sim ao conjunto que se seguiria. Pode-se imaginar isso pelo fato de que o tom geral dos textos é mais baixo do que o das Sentinelas dos períodos anteriores.

Além dos jornais, encontramos na coletânea uma seleção dos pronunciamentos de Barata como deputado nas cortes de Lisboa (entre dezembro de 1821 e setembro de 1822) e um conjunto de importantes textos, alguns dos quais têm autoria atribuída por Morel a Barata após minuciosa pesquisa. Entre eles, destacam-se um manifesto com uma crítica ferina ao decreto de $1^{\circ}$ de dezembro de 1822, que criou a Ordem do Cruzeiro, e uma dissertação sobre a Presiganga (1829), navio-prisão mantido pelo governo no Rio de Janeiro, e que é contundentemente combatida por Barata nesse e em outros textos.

A edição conta, como já foi indicado, com uma "Introdução" escrita pelo organizador, que é autor de outras importantes obras sobre Barata, e nesse texto expõe valiosas informações a respeito da trajetória, da memória e da iconografia, além de formular uma cronologia da vida e da obra do gazeteiro baiano. São reproduzidos os retratos disponíveis de Bara- 
ta, bem como os de outros políticos seus contemporâneos, pinturas das prisões em que esteve e mapas do Império do período em que ele atuou, além de outras imagens. É agradável para o leitor contar com elas no seu exemplar, mas penso que ficariam melhores se espalhadas no interior do volume, colocadas nos momentos em que esses personagens e paisagens são mencionados. Como foi feito com as reproduções de alguns exemplares originais do jornal e de partes de outros documentos, que estão inseridas por entre a transcrição dos textos.

Além dessa "Introdução", o organizador também elaborou comentários, que precedem cada uma das seis partes em que, em ordem cronológica, enfeixou os documentos. Trazem informações relevantes sobre os contextos em que foram elaborados os diversos escritos, bem como sobre a sua edição. Trazem também, assim como na "Introdução", algumas interpretações suas sobre os conteúdos dos textos, cuja propriedade o leitor pode averiguar ao lê-los, na sequência. Nesse aspecto, penso que um ponto merece ser problematizado. A afirmação, feita por Morel na "Introdução", de um "republicanismo (mais ou menos latente)" em Barata (p.17), é contrastada pela recusa, feita por esse em vários textos, da pecha de republicanismo que, segundo diz, os adversários tentavam impingir a ele e a seus correligionários, no intuito de incriminá-los (p.317). Na primeira fase da Sentinela, o autor é muito claro ao dizer que não faria diferença se o governo federativo fosse um Império ou uma República. O que importaria não seria o título do chefe do executivo, e sim a forma de representação e de entendimento de sua autoridade (p.531). $\mathrm{Na}$ segunda fase, Barata afirma que os adversários promoveriam a confusão entre federalismo e republicanismo, no intuito de incriminar os liberais federalistas (p.725). A defesa da República só aparece nos textos da última fase da Sentinela, em que, se Barata ainda escreveu, como acredita Morel, contou com a colaboração de um outro redator.

Os comentários do organizador são complementados por notas por ele elaboradas, boa parte das quais é de excelente qualidade: com informações densas e eruditas, auxiliam o leitor a pensar sobre o sentido de algumas passagens, sem buscar conduzir a sua interpretação. Entretanto, a qualidade do conjunto faz merecer uma reconsideração sobre a pertinência de algumas delas, numa próxima edição: aquelas em que o organizador simplesmente escreve em outras palavras, de modo diferente, um conteúdo que está no texto de Barata, e aquelas (poucas) em que percebemos um certo deslize interpretativo, em virtude de que a passagem comentada não dá margem precisamente ao comentário feito, que é mais revelador, talvez, do entusiasmo do comentador do que do sentido das argumentações-pregações de Barata

Essas observações não retiram os grandes méritos da organização e da edição do livro, cuja publicação é um acontecimento a ser saudado com entusiasmo, por pesquisadores e professores que lidam com história do Brasil e com o estudo do liberalismo. Faculta o acesso fácil a textos que são fontes primárias preciosas, nas quais são explicitadas propostas que participaram do intenso debate envolvido nas violentas disputas que marcaram a constituição do Estado liberal no Brasil. São textos valiosos para a pesquisa e para o ensino, merecendo, vários deles, figurar em programas não apenas de história 
do Brasil, como de disciplinas voltadas ao exame do pensamento liberal.

É um livro também importante para o leitor não especializado que tenha interesse pela história. Caso se disponha a percorrer tais páginas tão candentes, terá a possibilidade de conhecer um período dos mais conturbados na história do país, por meio da expressão viva e densa de um dos seus protagonistas mais instigantes. A perspectiva encontrada nesses textos é parcial, mas qual não é? Sabendo o leitor que se trata de um ponto de vista, pode travar um primeiro contato muito estimulante com as lutas da constituição do Estado liberal no Brasil.

Eide Sandra Azevêdo Abrêu é doutora em História, professora do Departamento de Ciências Sociais da Universidade Estadual de Maringá (UEM) e pós-doutoranda do Museu Paulista, da Universidade de São Paulo.@- eideabreu@uol.com.br 